\title{
Mechanical Characterization of Natural Fiber based Polymer Matrix Composite -A Review
}

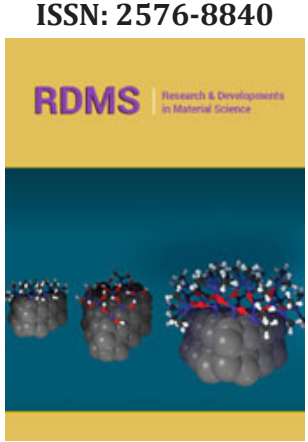

*Corresponding author: Shubham Mishra, Defense Materials \& Stores Research \& Development Establishment (DMSRDE), GT Road, Kanpur, India

Submission: 非 August 15, 2019

Published: 淟 August 23, 2019

Volume 11 - Issue 3

How to cite this article: Shubham $M$, Ashish D, Eswara P, Sanjay A. Mechanical Characterization of Natural Fiber based Polymer Matrix Composite -A Review. Res Dev Material Sci.11(3).RDMS.000765.2019. DOI: 10.31031/RDMS.2019.11.000765

Copyright@ Shubham Mishra, This article is distributed under the terms of the Creative Commons Attribution 4.0 International License, which permits unrestricted use and redistribution provided that the original author and source are credited.

\author{
Shubham Mishra ${ }^{1 *}$, Ashish Dubey ${ }^{1}$, Eswara Prasad $^{1}$ and Sanjay Agarwal ${ }^{2}$ \\ ${ }^{1}$ Defense Materials \& Stores Research \& Development Establishment (DMSRDE), India \\ ${ }^{2}$ Bundelkhand Institute of Engineering and Technology, India
}

\begin{abstract}
Environmental preservation has been a prominent concern for each country and numerous guidelines have been framed by International bodies. Due to obvious advantages use of polymer composites are increasing and automobile and aero industry are the biggest consumers. In the last few decades non degradable, hazardous fibers and matrices have been used in fabrication of composites for various applications. In recent time natural fiber such as Jute, Kemp, Cotton, Flax which are enormously found in nature are very much able to replace these hazardous fiber-based composites due to ecofriendly, biodegradable characteristics. They can also be used in hybrid composites with synthetic fibers to bring functionalities. This article is focused on some recent updates and findings in field of mechanical characterizations of natural fiber-based polymer composites.
\end{abstract}

\section{Introduction}

Polymer composites are primarily composed of matrix and reinforcement as glass fiber and carbon fiber. These types of fibers are known as synthetic or man-made fibers. These type of synthetic fibers based polymer composites have a certain drawback such as after being used these composites are not reusable and biodegradable. This is a major concern for environment, to counter this problem Natural Fiber (NF) has been introduced in polymer composites as reinforcement. Natural fibers are extracted from plants such as jute, cotton, flax, hemp, sisal, kenaf, pineapple, ramie, bamboo and banana as lingo cellulosic fibers. Classification of natural fibers is shown in Figure 1. Various natural fibers produced from plants have been shown in Figure 2. Natural fiber based composites are renewable, economical, completely or partially recyclable, and biodegradable. Their availability, renewability, less density and cost as well as reasonable mechanical properties make them a potential alternative of synthetic fibers [1]. Properties of selected natural fiber are as shown in Table 1 [2].

Table 1: Physical properties of various natural fibers.

\begin{tabular}{|c|c|c|c|c|}
\hline Fiber & Density $\left(\mathbf{g} / \mathbf{c m}^{3}\right.$ ) & Elongation (\%) & Tensile Strength (MPa) & $\begin{array}{c}\text { Elastic Modulus } \\
\text { (GPa) }\end{array}$ \\
\hline Jute & 1.3 & $1.5-1.8$ & $400-775$ & 26.5 \\
\hline Cotton & $1.5-1.6$ & $7.0-8.0$ & 400 & $5.5-13$ \\
\hline Flax & 1.5 & $2.7-3.2$ & $500-1500$ & 27.6 \\
\hline Kenaf & 1.45 & 1.6 & 930 & 70 \\
\hline Hemp & 1.47 & $02-A p r$ & 590 & $9.5-22$ \\
\hline Sisal & 1.5 & $2.0-2.5$ & $41-635$ & $61-128$ \\
\hline Ramie & 1.5 & $3.6-3.8$ & 1000 & $4.0-6.0$ \\
\hline $\begin{array}{c}\text { Softwood } \\
\text { Kraft pulp }\end{array}$ & 1.5 & 4.4 & 593 & 40 \\
\hline
\end{tabular}




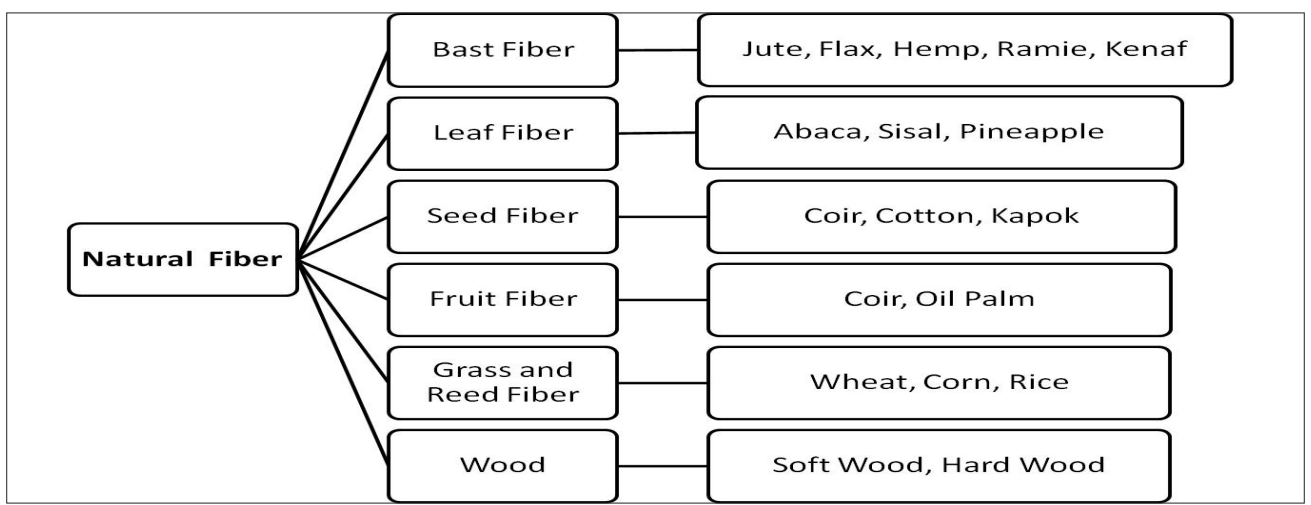

Figure 1: Classification of natural fibers.

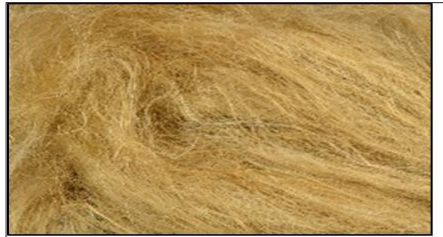

Jute

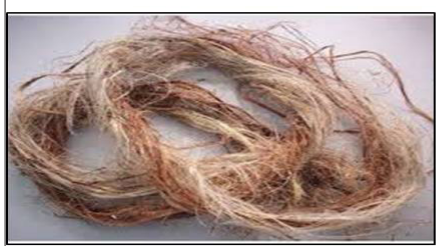

Kenaf

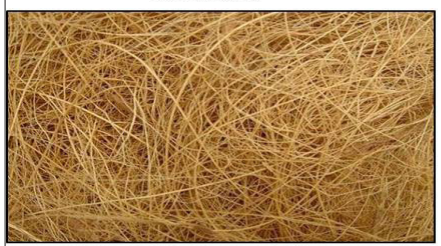

Coir

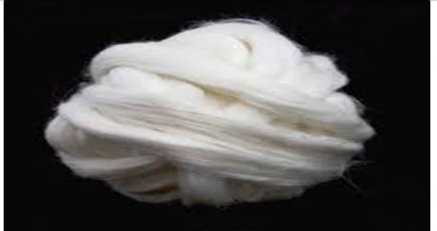

Cotton

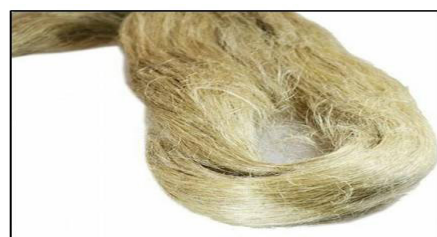

Hemp

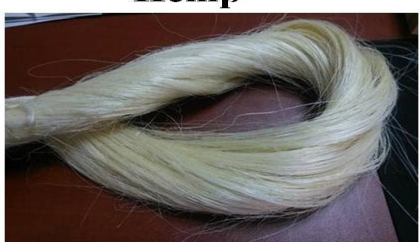

Sisal

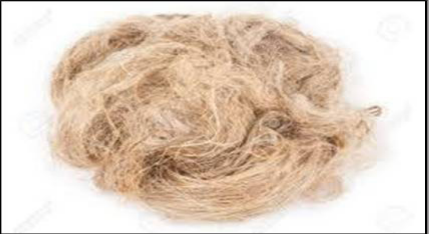

Flax

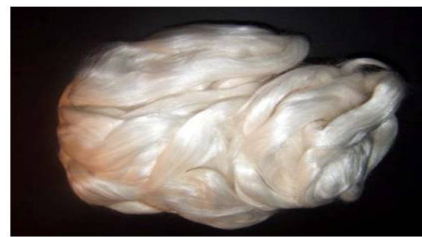

Ramie

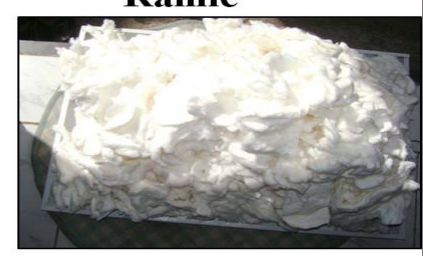

Softwood Pulp

Figure 2: Natural fibers produced from plants.

\section{Mechanical properties of natural fiber reinforced polymer composites}

The mechanical properties of any polymer composites depend on various factors such as
A. Physical properties of fiber.
B. Matrix (Thermosets and Thermoplastics) properties.
C. Fiber volume fraction in composites.
D. Interlayer bonding between matrix and fibers.
E. Orientation and geometry of fibers.

Various standardized and non-standardized mechanical tests [3] have been conducted by many researchers and scientists. Different fiber matrix combinations have been tried out such as abaca-polypropylene [4], bamboo- polylactic acid [5], bananaepoxy [6], flax-epoxy [7], jute-epoxy [8], kenaf-polyester [9]. Tensile strength and modulus of these fiber matrix systems are shown in
Figure 3.

Ajith et al. [10] have prepared fiber reinforced composites with jute fibers (fiber length $5-6 \mathrm{~mm}$ ) with two different resins polyester and epoxy. Tensile strength of the jute epoxy composite is more than jute polyester composite. Jute polyester composite took less time in processing as compared to jute epoxy composite. Sarikaya et al. [11] fabricated epoxy-based composites with different fibers birch, palm, and eucalyptus by combination of Resin Transfer Moulding (RTM) and moulded fiber production technique. Mechanical properties of these systems are shown in Table 2. Campana et al. [12] investigated the impact of post curing temperature $\left(100{ }^{\circ} \mathrm{C}\right.$, $120{ }^{\circ} \mathrm{C}, 150{ }^{\circ} \mathrm{C}$ ) on mechanical properties of flax-epoxy composite system. At high post curing temperature tensile properties slightly decreases. Sajeeb et al. [13] fabricated the composites in which khadi, Coconut Leaf Midrib (CLM) fibers with Melamine Urea Formaldehyde resin (MUF) and polyester resin. Result showed that MUF resin have better mechanical properties than polyester resin due to MUF resin with natural fibers have good binding property. 
A: Abaca+Polypropylene B: Bamboo+Polylactic acid

C: Banana+Epoxy

D: Flax+ Epoxy

E: Jute+ Epoxy

F: Kenaf+ Polyester

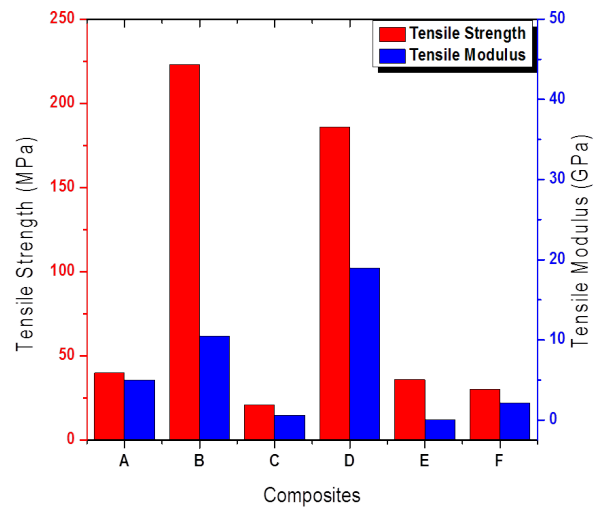

Figure 3: Tensile properties of different composites system.

Table 2: Mechanical properties of different fibers-based composites.

\begin{tabular}{|c|c|c|c|}
\hline \multirow{2}{*}{ Fibers } & \multicolumn{2}{|c|}{ Mechanical Properties } & Impact energy (J) \\
\cline { 2 - 4 } & Tensile Stress (MPa) & Bending Stress (MPa) & 0.105 \\
\hline Birch & 30 & 59 & 0.13 \\
\hline Palm & 42 & 69 & 0.124 \\
\hline
\end{tabular}

\section{Mechanical properties of natural and synthetic fiber based hybrid polymer composites}

There are many disadvantages associated with natural fiber reinforced polymer composites such as lower strength, lower modulus, and poor moisture resistance as compared to GFRP. Hybridization of natural fiber with synthetic fiber can improve the different property which is lacking before. Various research groups around the globe have done significant work in this field some of the recent work briefly reviewed here:

John et al. [14] studied variation of impact strength and compressive strength of unsaturated polyester based sisal/ glass hybrid composite with fiber loading. The result showed that with increased glass fiber percentage impact strength increased, but compressive strength decreases with increase in glass fiber percentage. Ramesh et al. [15] investigated the mechanical properties of three different composite sisal/GFRP, jute/GFRP, sisal/jute/GFRP samples and performed mechanical characterization such as tensile, flexural and impact test. The result showed that jute/GFRP composite sample having high tensile strength around $229 \mathrm{MPa}$ whereas high flexural strength achieved in sisal/jute/GFRP and maximum impact strength is achieved in sisal/GFRP sample around 18.67 Joules. Chaithanyan et al. [16] prepared the composite with 50:50 ratio sisal-glass fiber and resin combination. The tensile strength of is observed around 97MPa. Whereas hybrid composite with $40 \%$ sisal coir- glass fibers and $60 \%$ resin combination have high flexural strength $138.87 \mathrm{MPa}$ and high impact strength $1.429 \mathrm{KJ} / \mathrm{m}^{2}$. Sanjay et al. [17] fabricated the hybrid composite of jute-E-glass fiber reinforced epoxy composite. The result showed glass fiber as outer layers has better mechanical properties as compared to jute fiber as an outer layer. Jarukumjorn et al. [18] investigated the impact of glass fiber hybridization on the physical properties of sisal-polypropylene composite. Hybridization with glass fiber increases the mechanical property of composite and also increases the thermal stability. Tensile, flexural, and impact properties of the sisal-PP composites were improved due to interlayer adhesion between the fiber and matrix improved by compatibilizer.

Muthuvel et al. [19] fabricated the glass-jute fiber reinforced epoxy composites with different fiber lengths. The mechanical properties of composites were greatly influenced by fiber length. Fiber diameter with $3 \mathrm{~mm}$ shows better tensile strength, flexural property and impact property than others. Bharat et al. [20] has prepared two different composites first one is Aloe Vera-Ceramic Fiber Wool-Glass fiber with Epoxy resin matrix and other one is Sisal fiber-Ceramic Fiber Wool-Glass fiber with Epoxy resin matrix. Tensile strength, flexural strength and impact strength of Sisal fiber-Ceramic Fiber Wool-Glass fiber with Epoxy resin is more than Aloe Vera-Ceramic Fiber Wool-Glass fiber with Epoxy resin. Muhammad et al. [21] studied the mechanical properties of hybrid glass/Kenaf fiber-reinforced epoxy composite with the matrix modification using Liquid Epoxidized Natural Rubber (LENR) as a toughing agent. The results showed that the hybridization of Kenaf fiber with the glass fibre could produce better composite 
properties compared to the single Kenaf fiber system. Ramesh et al. [22] fabricated the Kenaf and glass fibers reinforced polymer composites with two different fiber orientations of $0^{\circ}$ and $90^{\circ}$. Mechanical property such as tensile strength, flexural strength and impact strength is evaluated, and the result showed that Kenafglass fiber reinforced hybrid composites with $90^{\circ}$ fiber orientation have more tensile and impact strengths than the composites with $0^{\circ}$ fiber orientation but the composites with $0^{\circ}$ orientation have more flexural strength than the composites.

\section{Conclusion}

Natural fiber reinforced composites due to its nonabrasive, ecofriendly and biodegradable characteristics have good future scope. Due to ease of availability, various types of fibers can be found in nature that is why mechanical properties vary from fiber to fiber. By altering the factors such as fiber orientation, length of fiber, manufacturing process and curing temperature desired properties can be tailored. Jute, sisal, flax and Hemp are mostly used fibers due to good mechanical characteristics. These fibers also easily hybridize with synthetic fibers (glass, carbon) when structural properties are the priority.

\section{References}

1. Elanchezhian C, Vijaya B, Ramakrishnan G, Rajendra KM, Naveen KV, et al. (2018) Review on mechanical properties of natural fiber composites. Materials Today: Proceedings 5(1): 1785-1790.

2. Dixit S, Goel R, Dubey A, Raj Shivhare P, Bhalavi P (2017) Natural fibre reinforced polymer composite materials-A review. Polymers from Renewable Resources 8(2).

3. Landel RF, Nielsen LE (1993) Mechanical properties of polymers and composites. CRC Press, Florida, USA.

4. Vilaseca F (2010) Biocomposites from abaca strands and polypropylene. Part I: evaluation of the tensile properties. Bioresour Technol 101(1): 387-395.

5. Sukmawan R, Takagi H, Nakagaito AN (2016) Strength evaluation of cross-ply green composite laminates reinforced by bamboo fiber. Compos B Eng 84: 9-16.

6. Arthanarieswaran V, Kumaravel A, Kathirselvam M (2014) Evaluation of mechanical properties of banana and sisal fiber reinforced epoxy composites: Influence of glass fiber hybridization. Mater Des 64: 194-202.

7. Tensile properties of flax FRP composites (2017) In: Betts D, Sadeghian P, Fam A (Eds.), ( $6^{\text {th }}$ edn), Asia-Pacific conference on FRP in structures, Australia.

8. Bisaria H, Gupta M, Shandilya P, Srivastava R (2015) Effect of fibre length on mechanical properties of randomly oriented short jute fibre reinforced epoxy composite. Mater Today Proc 2(4-5): 1193-1199.

9. Ismail AE, Aziz CA, Aswadi M (2015) Tensile strength of woven yarn kenaf fiber reinforced polyester composites. J Mech Eng Sci 9: 1695-1704.

10. Gopinath A, Senthil Kumar M, Elayaperumal A (2014) Experimental investigations on mechanical properties of jute fiber reinforced composites with polyester and epoxy resin matrices, Global congress on manufacturing and management. Procedia Engineering 97: 2052-2063.

11. Sarikaya E, Çallioğlu H, Demirel H (2018) Production of epoxy composites reinforced by different natural fibers and their mechanical properties. Composites.

12. Campana (2017) Effect of post curing temperature on mechanical properties of a flax fiber reinforced epoxy composite. Composites.

13. sajeeb am (2018) evaluation of mechanical properties of natural fiber reinforced Melamine Urea Formaldehyde (MUF) resin composites. Materials Today: Proceedings 5(2): 6764-6769.

14. John K, Venkata Naidu S (2004) Sisal fiber/glass fiber hybrid composites: The impact and compressive properties 23(12): 1253-1258.

15. Ramesh M, Palanikumar K, Hema CK (2013) Mechanical property evaluation of sisal-jute-glass fiber reinforced polyester composites. Composites Part B: Engineering 48: 1-9.

16. Chaithanyan C, Venkatasubrahmanyan H, Raghuraman S, Panneerselvam $\mathrm{T}$ (2013) Evaluation of mechanical properties of coir sisal reinforced hybrid composites using isophthalic polyester resin. International Journal of Innovative Research in Science Engineering and Technology 2(12).

17. Sanjay MR, Yogesh B (2016) Studies on mechanical properties of jute/Eglass fiber reinforced epoxy hybrid composites. Journal of Minerals and Materials Characterization and Engineering 4(1): 15-25.

18. Jarukumjorn K, Suppakarn N (2009) Effect of glass fiber hybridization on properties of sisal fiber-polypropylene composites. Composites: Part B 40(7): 623-627.

19. Muthuvel M, Ranganath G, Janarthanan K, Srinivasan K (2013) Characterization study of jute and glass fiber reinforced hybrid composite material. International Journal of Engineering Research \& Technology 2(4).

20. Bharat KR, Abhishek S, Palani Kumar K (2017) Mechanical property analysis on sandwich structured hybrid composite made from natural fibre, glass fibre and ceramic fibre wool reinforced with epoxy resin. IOP Conf Series: Materials Science and Engineering 205: 012015.

21. Muhammad YH, Ahmad S, Abu Bakar MA, Mamun Hans AA, Heim P (2015) Mechanical properties of hybrid glass/ kenaf fibre-reinforced epoxy composite with matrix modification using liquid epoxidized natural rubber. Journal of Reinforced Plastics and Composites 34(11): 896-890.

22. Ramesh M, Nijanthan S (2016) Mechanical property analysis of kenaf-glass fibre reinforced polymer composites using finite element analysis. Bull Mater Sci 39(1): 147-157. 